\title{
A Participatory Management Model for Flood-Risk Communication (PMMFRC) in Davao City, Philippines
}

\author{
Karen Joyce G. Cayamanda and Merlyne M. Paunlagui
}

\begin{abstract}
Vulnerable communities of Davao City, Southern Philippines has experienced flooding that leads to catastrophic effects costing damage to properties and loss of lives. Communities need to build its resiliency to respond to flooding and mitigate its negative impacts. Policy makers and leaders need to regularly review and update its existing policies to address gaps and promote effective community engagement.

This paper highlights the development of the communication management framework based on the results from the qualitative approaches of document analysis, examination of relevant secondary data and the key informant interviews conducted among the heads and representatives of the identified agencies involved in the risk reduction and disaster management of the city. Results of the study revealed that Davao City implements a top-down communication system for risk reduction management which has little or no room for transactional interaction between the source of the message and the local communities. Messages have been found to be unfiltered and interoperability mechanism has been found only at the level of the implementing agencies. The study, therefore, proposed a participatory management model for flood-risk communication (PMMFRC) for flood-vulnerable communities towards risk reduction.
\end{abstract}

Index Terms - communication management framework; disaster resiliency; flood-vulnerable communities; participatory management; risk reduction.

\section{INTRODUCTION}

O'Neill [1] reported that traditional approaches to risk communication are being used by disaster managers for community education. Using the top-down approach for awareness and preparedness are considered useful but may not acknowledge the context-specific perceptions of the community on the risks they face and discover the capacities of the communities to respond to these risks. There is a need to shift from an emergency response to a "proactive risk management" approach integrating a participatory approach and community safety as a total system with all the elements involved being integrated into the entire system. Using risk communication as a tool for effective risk management at the level of the communities can enhance community preparedness and reduce the risks triggered by flooding.

Moreover, Allen [2] viewed that the communities are the appropriate level for community-based disaster preparedness intervention since it has the capacity to collectively identify problems, take decisions and act on them. There is a growing consensus among researchers and planners to incorporate local communities in disaster risk management and climate change adaptation planning [3]-[6], yet its actualization largely remains a dream [7]. The Philippines, over the last decade, ranked $10^{\text {th }}$ in the 2007 Global Risk Index [8], has been considered as one of the most vulnerable countries in the world due to the occurrence of recent severe disasters. This paper integrates the results of the qualitative and quantitative analysis in proposing a community-based flood risk communication management framework appropriate for the flood vulnerable communities.

\section{LITERATURE REVIEW}

For many years there has been an imbalance between the resources invested in disaster response and those dedicated to the prevention and mitigation of disasters. The world community and most individual countries have preferred to tackle the problem by responding to adverse events rather than anticipating them. There are several reasons why this position has become harder and harder to maintain. Disasters and development are closely linked. When disasters occur, it can either destroy or disrupt development opportunities. Similarly, development schemes can both increase and decrease vulnerability of the communities [9]-[13]. It was observed that disasters were seen in the context of emergency response - not as part of long-term development programming. Development requires institutional and structural transformations of societies to speed up economic growth, reduce levels of inequality and eradicate absolute poverty. Overtime, the effects of disasters can seriously degrade a country's long-term potential for sustained development and cause governments to substantially modify their economic development priorities and programs [9].

\section{A. Models for Disaster Studies}

Previous approaches have been utilized from the structural models [14]-[16] to models of social motivation and protection [17]-[20], some models highlight the role of social networks, policies and governance [5], [21]-[24] and models that emphasize human and social ecological elements [25][30]. Among all these varied approaches, the significant role of risk communication has been emphasized and the consideration of working towards at "bottom-up" approach is recommended.

Alexander [26] emphasized that human ecology posits a relationship between people and their environment in which 
technology can overcome some of the difficulties, but nature is not easily dominated and hence there must be adaptation to extremes. In the original work, the model shown in Figure 1 is based on the rational man who makes economic decisions as an optimizer, by maximizing opportunities to gather information, or a satisfier, by choosing rationally from a limited range of options. Evidently, this model allows no leg room for cultural or ideological variations and only the most limited opportunity for perception to govern choice. In reality, there is a constant dialectic between factors that increase risk (for example, stronger hurricanes, building new settlement in vulnerable areas, water management that increases downstream flood risk) and those that diminish it, the actions of disaster risk mitigation. Furthermore, he remarkably noted that few academic studies of disaster tackle the problem of culture being an assemblage of shared beliefs, opinions, social characteristics and attitudes. Thus, it is extremely difficult to measure in any social scientific way. Reason may be that it is an elusive and multi-faceted concept that changes with social context. In addition, culture as a set of nested phenomena, thus, we respond to different cultures related to national, regional and local settings; peer groups, families and workplaces; ethnic and social groups; gender and race; and interest groups. Moreover, culture undergoes a constant process of metamorphosis as it adapts to the changing circumstances of the modern world and how we are able to interpret it. As a result, there are very few reliable measures of culture. It is nonetheless highly important. If one wants to promote change, success is more likely if it is compatible with the prevailing culture, while if it runs against the culture, the adaptive process is likely to be blocked for apparently illogical reasons.

Simon's model [26] shows that culture is dynamic, thus, a lot of factors can still be utilized to explain the relationships of man, environment and the institutions. These factors are important sources of cultural uniformity that would allow the community-based comprehension, appreciation and response to disaster situations. Hence, it encourages the idea that communities can help develop participative approaches in building "bottom-up" strategies.

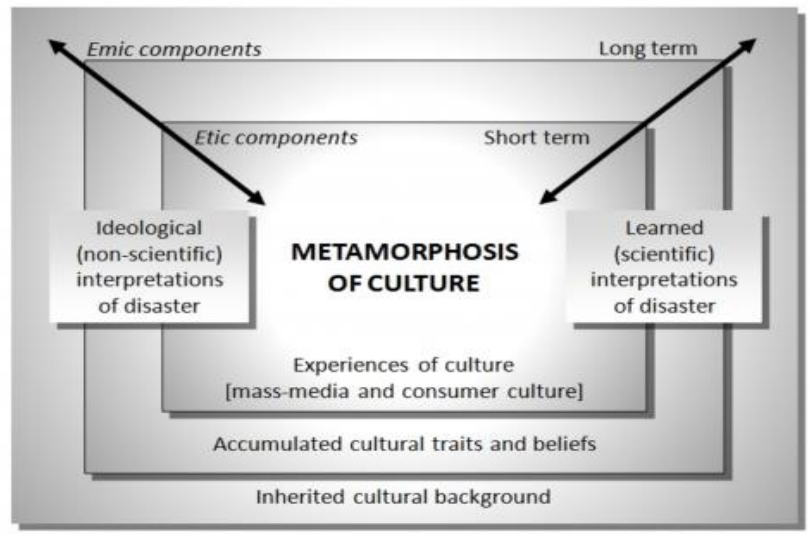

Fig. 1. The architecture and metamorphosis of human culture (Simon, 1956 as cited in Alexander [26]).

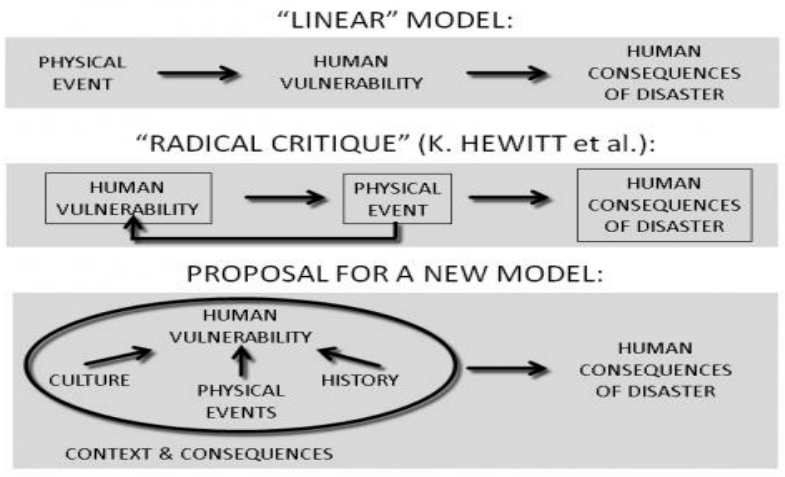

Fig. 2. Possible evolution of models of disaster [26].

Similarly, social vulnerability models to disaster [26] can be utilized for future disaster resilience studies that can further examine the relationship between man and environment towards a human-ecological dimension. In the process, the Systems approach can better explain and show the inter-relationship and integration of man, environment and the institutions. Figure 2 shows that the existing approaches in disaster studies are linear, thus, fails to look at the human ecology aspect of the situation. Consequently, Alexander [26] proposed an alternative approach to the study of disaster resilience to address this gap in the area of disaster and resilience studies showing the possibility of evolution of human ecological models of disaster from a linear to a transactional approach, incorporating culture as part of the equation, thereby, contextualizing the study of disaster and its impact to humans and environment. Increasing knowledge of disasters and the social processes involved, and the complexity of life in the early 21 st century, suggest that a new model ought to be formulated (proposed model). The vulnerability of human socio-economic systems is acted upon by physical hazards (whether natural or anthropogenic), as well as cultural and historical factors. The plexus of the context and consequences of these associations is what determines the form, entity and size of any ensuing disaster [26]. In summary, a social-ecological approach provides a deeper understanding of the complex, trans-disciplinary and dynamic processes of adaptation and counter-adaptation highlighting the interplay of human and ecological systems integrating the scientific-physical systems knowledge, symbolic-experiential and socio-cultural systems [30].

Coupled systems of humans and nature are complex, in terms of how they anticipate and respond to natural disasters. These complexities present great uncertainties for many facets of society. The capacity to deal with the types of uncertainty and surprises will require novel approaches, creative combinations of strategies, and the ability to adapt in a changing environment. Accelerating learning and supporting novel approaches that limit vulnerability and expand our understanding of the occurrence and impacts of natural disasters seem to be critical components of building community resilience. Natural disasters are common occurrences among Asian countries like the Philippines. Urban flooding, in fact, occurs more frequently which is mostly attributed to unabated urbanization. Its effects are catastrophic in proportion costing damage to properties and loss of lives. Urban vulnerability is a priority concern; communities must build resiliency to respond to disasters and mitigate its negative impacts. Using the case of the 2011 
flashflood experience of Davao City, Southern Philippines, the Crunch model was used to explore the urban vulnerability of a community to natural disasters [31]. Using the model, the factors leading to progression of vulnerabilities were determined and the institutional and social dynamics during the flooding incident were examined. Results show that the positive social relationships resulted to quick response by the concerned groups and institutions. The study reflects that communities and various groups exhibited a high sense of social capital, stronger alliance and trust with the concerned government institutions in Davao City, despite recorded 29 casualties. However, post disaster reports indicate the absence of communication and coordination protocols during the rescue and recovery stages. Thus, this chapter recommends a community-based flood-risk communication system that would enhance community resilience towards reduction of urban vulnerability to flooding.

\section{B. Role of institutions and communities in communicating and managing risks and disasters}

The communities learned the hard way from the flashflood disaster experience of 2011 and immediately worked on the revival of their Disaster Reduction Management Team (DRMT). Programs for risk intervention were also revived and a more aggressive communication intervention for awareness and strengthen the capacity of vulnerable people of their barangay. These programs were made better in cognizance of the RA 10121. From a responsive approach, the community transformed into both responsive and proactive approach towards dealing with disasters, especially floods. Moreover, risk intervention programs were included in the post disaster strategies [32]. The flashflood incident revealed that Davao City is naturally a flood prone area. This is manifested by its physical characteristic where the entire land area of the city drains itself towards the Gulf Davao River and the Talomo River, the two rivers considered as the most important river basins in the city [33]. The serious implication of this is magnified with the high population density found along the banks or nearby the river tributaries for example the housing, business and institutional areas affected by the Matina Flash Flood. Consequently, the 2011 flash flood in Matina area exhibited a higher level of social capital among residents, various groups and institutions in Davao. The response was quickly mobilized. One of the advantages is that the City has highly trained personnel and possess sophisticated search and rescue equipment through its Central 911. Their strength plus community mobilization made disaster response not only quick but effective as well.

However, it was noted that the lack of communication protocols led to the casualties recorded, mostly, vulnerable groups, i.e., women, children and senior citizens. The damage may not be as high as compared to other areas with other areas in similar situation, but flood occurs unexpectedly without warning and lead time. In addition, the case study on the Davao City flashflood of 2011 based on the records of testimonials from the victims, reports from the government agencies and documentation of the disaster incident revealed the immediacy of response and action of the different agencies and concerned organizations to assist the affected areas within the first six hours of the disaster. Massive evacuation efforts were done to put victims on safer grounds, first-aid teams immediately addressed medical concerns upon arrival at the evacuation areas. The barangay captain immediately initiated community kitchen to feed victims. Furthermore, it was observed that relief goods from both government and non-government agencies, church-based sectors and concerned individuals and groups arrived within the first 24-hours from the onset of the disaster. Reports also reveal that various organizations and NGOs, in addition to the government agencies were identified as responders of the disaster. However, despite the influx of agencies and organizations that were involved in the recovery and response, the disaster resulted to some casualties. The case of the 2011 Davao flashflood revealed that the lack of clear guidelines on how to manage and coordinate the different organizations in responding to the disaster, the gap of six hours resulted to damages and loss of lives. The communication protocol was not in order, thus, making the communities vulnerable to the disaster. Despite the observed efforts and the preparedness level among the concerned agencies and sectors, initial post disaster studies on the flashflood incident revealed that there is a low awareness and level of risk perception among the communities. Further, there was a lack of communication protocol that led to the negative impact of the disaster incident. Hence, the gap of six hours before the initial response arrived could have been addressed if the community is aware on the risk level they are facing. Another revealing factor contributing to the impact of the disaster was the lack of communication management and protocols among the agencies and organizations to properly address the synchronization and integration of the recovery and response activities as observed by the affected residents. There was also the observance of poor coordination across the inter-agency response system. This was also highlighted in the post crisis report prepared by the Davao City Disaster Risk Reduction and Management Office (CDRRMO) as one of the major areas that needs further improvement [34].

\section{Methodology}

The study was conducted to primarily (1) describe the existing protocols in the risk communication systems and (2) identify the corresponding network among the lead and implementing agencies of Davao City, Southern Philippines. The qualitative method of data generation for this part consisted of quotations from the narratives documented through key informant interviews and focus group discussions, utilizing a semi-structured interview approach for both approaches. List of questions have been prepared to ensure that the same basic lines of inquiry are asked from all informants, but the researcher has the flexibility [35] to modify and explore, probe or build further conversations for clarification and illumination purposes. Using the secondary and primary data from key informant interviews and focus group discussions, policy and content analysis was used. This paper presents the current risk communication system of Davao City. Specifically, it describes the structure and role of the agencies involved in the disaster risk reduction management such as the Public Security and Safety Command Center (PSSCC); the City Disaster Risk Reduction and Management Office (CDRRMO) and Central 911; and, the LIGA-Association of Barangay Captains (LIGA-ABC), 
its policies and procedures and the flow of information among its channels. Moreover, it includes an examination of the inter-related coordination, mechanisms, and interactions among the key agencies from the data collected from the focus group discussions attended by the barangay captains and purok leaders of the flood vulnerable communities.

Guided by Kasperson's [36] Social Amplification of Risk Framework (SARF), this part of the data analysis focused on the role of the information flow through the "filtering stations", in this case, the agencies being the source of the information and how they cascade the information to the affected or concerned communities and how far is the extent of the spread of impact of the message transmitted. Although SARF proposes a mechanism through which risk responses arises from interactions among various social actors, this particular analysis is limited to the presentation of the structural flow of the communication to primarily describe the current and existing operationalization of risk communication in Davao City.

In analyzing the organizational approach on the flow of communication, the Network Analysis will be guided by the organizational theory espoused by Weber as regards Bureaucracy and elements in organizational transactions. Specifically, the Organizational Information Theory (OIT) acknowledging the role of the flow of communication and places strong emphasis on the dynamic process of transmission and reception of inputs emphasizing the importance of human interaction as central to processing information, thus, focusing on the communication process rather than the role of the communicators [37]. Moreover, this was combined with Network Theory [38], specifically looking into the "social structures created by communication among individuals and groups". It can either be formal networks which are prescribed by organizational rules such as bureaucratic structure or emergent networks that are informal channels of communication built not within the confines of the prescribed organizational rules but by "regular and daily contact among members".

\section{RESULTS AND DISCUSSION}

\section{A. The Risk Communication Management System of Davao City}

The results of the qualitative study have revealed that Davao City is compliant and utilized the NDRRMP as guide to implement RA 10121 [39]. Consequently, its NDRRMC has been re-activated to monitor and implement disaster risk reduction programs. The NDRRMP adopts a top-down method of implementation from policies, structures, coordination mechanism and program implementation. It follows that the functions and tasks being delegated to the concerned agencies also adheres to this structure. Figure 3 shows that the communication is cascaded from the top thereby, messages emanate from the national level to the municipal and down to barangay level. The current situation of the risk communication system of Davao City is compliant to the Republic Act 10121, however, the programs and strategies can still be improved to minimize the risks among the residents of the flood-vulnerable communities.
O'Sullivan [40] stressed that as long as the communication flow is only top-down, then no change is likely to happen. For risk communication to be translated into an effective disaster risk reduction strategy, community engagements must be encouraged. Moreover, external factors like political and social consequences and other social dynamics that lie within the government, key agencies and authorities must be considered to provide a holistic transactional process to be materialized [20], [41]. Moreover, the modified network analysis of this study shows that the communication systems and protocols of Davao City have little or no room for direct transactional interaction between the main source of the message, the NDRRMC and the local communities which are directly affected by flooding. In addition, messages or communication tools emanating from the original source have been found to be cascaded towards the lower level receivers without any alteration or modifications appropriate for the local residents.

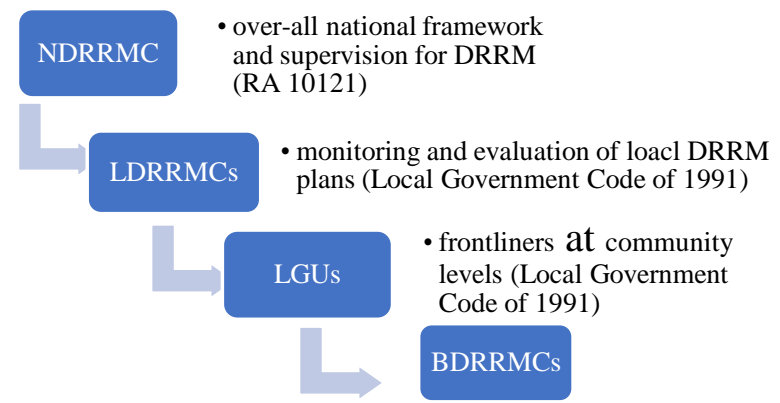

Fig. 3. Philippine's DRRM Structure and Flow of Communication [39].

Figure 4 shows the transactional process among the lead agencies reflecting the communication network of Lindell and Perry [42]. Specifically, NDRRMC being the original source and DILG being the intermediate institution relay the information to LIGA-ABC, PIA and PSSCC; the Office of the City Mayor as the intermediate 2 relaying the information to PSSCC, OCD and RDCC while CDDRMO being the ultimate receiver 1 coordinates with PSSCC to ensure relay of information to response units like the 911 and $\mathrm{CHO}$. Moreover, the network of communication systems was not yet well-defined at the barangay levels. From the survey and the FGDs conducted, residents have revealed that although they are aware and appreciative of the efforts being done by the barangay in terms of awareness and preparedness as well as response during flooding incidences, they would appreciate if they can also participate and give inputs on the DRR strategies based on their experiences and current adaptation practices.

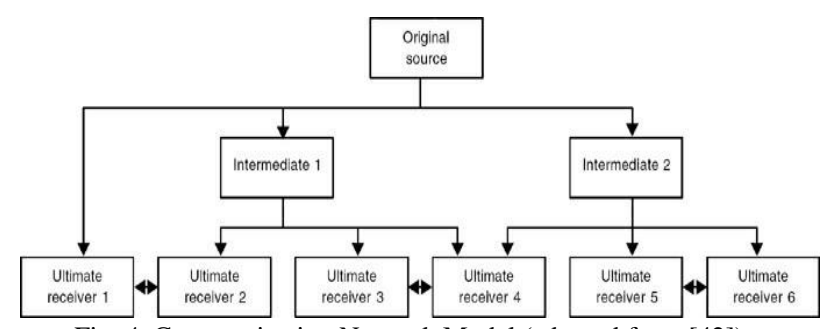

Fig. 4. Communication Network Model (adopted from [42]). 


\section{B. The Policies and the Agencies involved in DRRM}

The Disaster Risk Reduction and Management Act of 2010 which replaced Civil Defense Act of 1954, provides the legal and institutional basis for its framework. It gives the mandate of a top to bottom structure from the national to the local units or barangay. The National Disaster Risk Reduction and Management Council (NDRRMC) is empowered with the policy-making, coordination, integration, supervision, monitoring and evaluation functions. Although it is headed by the Secretary of the Department of National Defense, it adopts a multi-sectoral representation comprising of sector ministries, civil society organizations and the private sector. The NDRRMC is replicated at the sub-national levels at provincial being the Local Disaster Risk Reduction and Management Office (LDRRMO), city and municipal levels as the City Disaster Risk Reduction and Management Council (CDRRMC) and at the barangay levels with the Barangay Disaster Risk Reduction and Management Committee (BDRRMC). The LDRRMO provides the technical support to the CDDRMC and BDRRMC [39]. Consequently, Republic Act 10121 or the National Disaster Risk Reduction and Management Act together with the NDRRMP Plan of 2010 provides the legal basis for policies, plans and programs to deal with disasters. By law, the Office of the Civil defense formulates and implements the NDRRMP and ensures that the physical framework, social, economic, and environmental plans of the communities, cities, municipalities, and provinces are consistent with such plan [39]. The framework envisions a country of "safer, adaptive, and disaster-resilient Filipino communities toward sustainable development", with the coverage of four thematic areas, namely: (1) Disaster Prevention and Mitigation, (2) Disaster Preparedness, (3) Disaster Response and (4) Disaster Rehabilitation and Recovery. The National Disaster Risk Reduction and Management Committee (NDRRMC)'s assessment and identification of the flood risk areas are based on the hazard maps developed by different agencies such as the United Nations, and the Meteorological and Geosciences Bureau (MGB) which shows the vulnerable areas for natural hazards in the Philippines. Other sources include: PAG-ASA and Project NOAH (Nationwide Operational Assessment of Hazards) of DOST that constantly monitor the rain levels and weather patterns in the country's area of responsibility. This allows for the identification of coming typhoons. In the past years, the Philippines had experienced some destructive typhoons which includes Pablo, Pepeng, Santi, Sendong, Ondoy, Yolanda --- which resulted to damage of properties, loss of lives, loss of livelihood.

At present times, the NDRRMP serves as a guide how to carry out: (1) Disaster Prevention and Mitigation; (2) Disaster Preparedness; (3) Disaster Response; and (4) Disaster Rehabilitation and Recovery. It was developed to achieve "disaster-resilient and safe Filipino communities" [43], [44], [45]. The NDRRMP base their risk assessments and decisions that determine the Philippines' vulnerability to natural disasters through geohazard maps and constant communication with key agencies. In addition, barangaybased efforts in the Philippines have also been developed in compliance to the NDRRMP mandate through the creation of the Barangay Disaster Risk Reduction and Management Plans (BDRRMP) with the major function of "protecting public and private organizations from any forms of disasters, hazards and other risks". Furthermore, the BDRRMCs have been created with organizational structures with stipulated functions at the community levels. Its plans and projects are implemented by the barangay officials or through partnerships with the private sectors, the NGOs, businesses, local and international organizations. As such, pre-disaster activities at the community levels include information, education and communication (IECs) on areas of detecting, communicating, and preparing for disasters [46]-[47].

The Davao City Disaster Risk Reduction and Management Council (DRRMC) was created as provided for in the Philippine Disaster Risk Reduction and Management Act of 2010. RA 2010 laid the basis for a paradigm shift from just disaster preparedness and response to disaster risk reduction and management (DRRM). Table 1 shows the three major agencies involved in disaster-related concerns of the city, as follows: the Public Safety and Security Command Center (PSSCC); the City Disaster Risk and Reduction Management Office (CDDRMO) and the LIGA-Association of Barangay Captains (LIGA-ABC) of Davao City.

\section{Network Analysis and Inter-operability of the agencies involved}

The challenge in any communication to be effective is the identification of the crucial role of its interdependent elements of source-message-channel-receiver to achieve a successful outcome. In the case of risk communication, the greater challenge is the identification of the target audience as a major consideration prior to the designing and planning the appropriate methods and channels to relay the risk messages. It is also necessary to identify the relevant information in the different stages of the disaster cycle.

Figure 5 shows the DRRM framework of Davao City with the specific tasks according to the disaster management cycle. The plans and strategies vary based on the different outcomes expected of the agencies. In the case of the risk communication, it is targeted among the most vulnerable communities. Specifically, for flooding concerns, the results of the key informant interviews and focus group discussions reveal that the focus or priority is to address the information campaign among the top five (5) flood vulnerable communities of Davao City as reflected in the hazard map.

Comfort \& Kapucu [24] emphasized the need for integration as the number of organizations engaged in disaster related concerns. Achieving coordinated action among disparate group of actors depends fundamentally on their access to timely, valid information and their capacity for information search, exchange, absorption, and adaptation Moreover, a study stressed the significant role of the interplay of institutional partnerships and inter-governmental network system that encourages collaboration in the disaster management and risk reduction strategies [48].

The PSSCC serves as the center for coordination on matters of public safety with linkages to the following government agencies: (1) Davao City Police Office (DCPO) - on crime prevention, suppression, and investigation; (2) City Traffic and Transportation Management Office (CTTMO) - on traffic management and enforcement; (3) City Health Office (CHO) and City Social Services and Development Offices (CSSDO) - on actual and emerging 
health emergencies and management of victims and emergency shelters; (4) Central 911, Bureau of Fire Protection, Red Cross and volunteer organizations - on all types of rescue services, including fire prevention and suppression, and hazardous materials response; (5) Davao
City Disaster Coordinating Council, Office of the Civil Defense, and Regional Disasters Coordinating Council - on planning and responding during calamities, disasters, and other special events.

TABLE 1: MATRIX OF THE AGENCIES, LEGAL BASIS AND ITS FUNCTIONS IN DISASTER OPERATIONS

\begin{tabular}{|c|c|c|}
\hline AGENCY & LEGAL BASIS & TASKS/FUNCTIONS \\
\hline PSSCC & $\begin{array}{l}\text { Office of the Mayor } \\
\text { Executive Order \#18 } \\
\text { Series of } 2012\end{array}$ & $\begin{array}{l}\text { - Serve as the command, control and coordinating area during daily operations, crisis situations and } \\
\text { combined security operations. } \\
\text { - Develop, create and operate an alternate command and control unit as the need arises. } \\
\text { - Maintain a constant and up-to-date city risk assessment on criminality, terrorism and emergencies. }\end{array}$ \\
\hline CDRRMO & RA 10121 & $\begin{array}{l}\text { - Design, program and coordinate disaster risk reduction and management activities consistent with the } \\
\text { national council's standards and guidelines. } \\
\text { - Facilitate and support risk assessments and contingency planning activities at the local level. } \\
\text { - Consolidate local disaster risk information which includes natural hazards, vulnerabilities and climate } \\
\text { change risks and maintain local risk map. } \\
\text { - Organize and conduct trainings, orientation and knowledge management activities on DRRM at local } \\
\text { levels. } \\
\text { - Operate a multi hazard early warning system linked to DRR to provide accurate and timely advise to } \\
\text { national or local emergency response organizations and to the general public through a diverse } \\
\text { communication approach. } \\
\text { - Identify, assess and manage hazards, vulnerabilities and risks that may occur in their locality. } \\
\text { - Disseminate information and raise public awareness about those hazards, vulnerabilities and risks, their } \\
\text { nature, effects, early warning signs and counter-measures. } \\
\text { - Establish linkage/network with other LGUs for DRR and emergency response purposes. } \\
\text { Establish a Barangay DRRMO with similar functions and tasks at the community levels. }\end{array}$ \\
\hline $\begin{array}{l}\text { LIGA- } \\
\text { ABC }\end{array}$ & $\begin{array}{l}\text { Sec } 491 \\
\text { Local Government } \\
\text { Code of } 1991\end{array}$ & $\begin{array}{l}\text { - Give priority to programs designed for the total development of the barangays and in consonance with the } \\
\text { policies, programs and projects of the national government. } \\
\text { - Assist in the education of barangay residents for people's participation in local government administration } \\
\text { in order to promote united and concerted action to achieve country-wide development goals. } \\
\text { - Serve as a forum of the barangays in order to forge linkages with government and non-government } \\
\text { organizations thereby promote the social, economic and political well-being of the barangays. } \\
\text { - Exercise such other duties and functions which will bring about stronger ties between barangays and } \\
\text { promote the welfare of the barangay inhabitants. }\end{array}$ \\
\hline
\end{tabular}

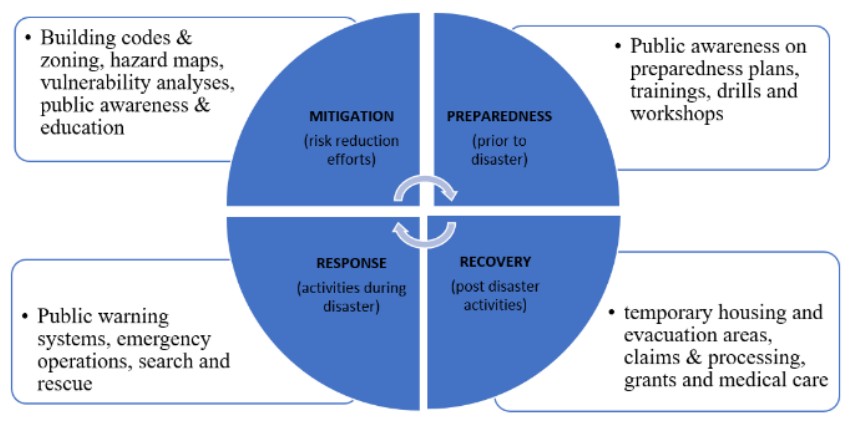

Fig. 5. DRRM Framework of Davao City.

Davao City is known and prides itself for having a Central 911 for its emergency and response concerns since 2002. However, the presence of this center was not sufficient to address the concerns of the Davao City flashflood which struck the Matina area on 2011 that resulted to casualties and damage to properties and disrupted economic activities of the affected areas. This disaster posed a challenge to the current set-up of the City as regards safety and security of its constituents [31]. Thus, establishing the intertwined role of the 911 vis-à-vis the Disaster Risk and Reduction Management Office under one office is compliant with the US standard for emergency response [49]. To perform interorganizational integration, organizations and systems must be able to interoperate [50]. Interoperability was first defined by the United States Department of Defense in a 1977 North American Treaty Organization document as "the ability of systems, units or forces to provide services to and accept services from other systems, units or forces and to use the services so exchanged to enable them to operate effectively together" [51]. Highlighting the value of interoperability in each responder towards any eventuality being handled by the entire network of agencies, Mr. Boquiren visualized the coordination among agencies using a diagram as shown in Figure 6 and highlighted the significant role of the City Mayor, the head of the PSSCC in overseeing and managing the entire operation. The Center has the mandate to maintain and sustain the inter-operability of the different agencies for a better management of communication and related concerns in addressing security and safety of the public.

The coordination that takes place in Davao City demonstrates the significant role of interoperability of the agencies working towards the safety and security of the people from the flood vulnerable communities. As far as the CDRRMO is concerned, the City is prepared and has addressed the problem of communication management at the City level. The City has the necessary equipment, evacuation centers are in place, and the agencies like the City Social Services Department Office and City Health Office know their roles and responsibilities when disasters occur. Despite the preparedness, availability of sophisticated equipment, and plan for worst case scenario, the key informant believed that the best solution is to evacuate the residents of flood vulnerable areas.

The above discussion highlights the significant role of the agencies in communicating risk and make people aware and be alert during impending eventualities. It was also mentioned that aggressive campaigns are being done despite the observed lack of manpower and at times funding to implement the strategies to increase the level of preparedness 
and awareness. Moreover, they have not been able to develop communication tools inasmuch as they could. They have plans of developing localized posters, brochures, and pamphlets, but unable to do so because of limited resources. Thus, the CDRRMO concentrates more on other channels of communication. Significantly, radio communication becomes a major channel, followed by social media and cellular phones to communicate with the key persons at the community levels. Moreover, CDRRMO relies more "disaster response" through coordination with other agencies like the City Engineer's Office to access needed heavy equipment and additional assistance from the City Police Department during evacuation.

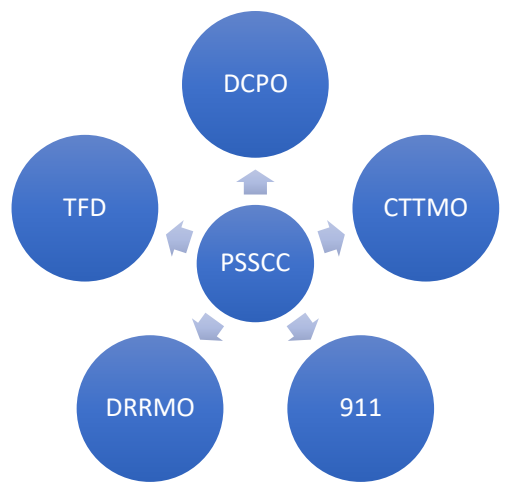

Fig. 6. Interoperability framework of the PSSCC [49].

The CDRRMO, through the key informant, has expressed their appreciation on the role of the academe and other institutions which transform the technical materials into simple messages that can be readily transferred to the communities. He cited the University of the Philippines' (UP) Project Noah which have popularized the technical information. However, there are missing information that reflect the real situation in the communities. That is where, they rely on the experiential knowledge from the community itself. Direct interaction with the community makes them understand the real-time situations which can help them develop more approaches appropriate to the situation of the flood vulnerable communities. Moreover, there is a need to transform the reactive approach to a proactive approach in terms of disaster and related concerns.

Moreover, the key informant believed that there are still areas for improvement in responding to flooding and other disasters. Specifically mentioned was the need to intensify the information and education communication (IEC) as well as the development of communication protocols to address the transmission of information at the community levels. Moreover, these risk messages should be converted from generic messages into localized messages applicable to their context and experiences for better appreciation of the residents. This is where the CDRRMO needs assistance in translating the technical and scientific information for the residents to understand and appreciate. As a result, many IEC materials from the national agencies are wasted. The key informant also shared that national government agencies should give the information without the need to analyze the technical outputs for faster response. The key informant is referring to the automatic weather station and radar from the Department of Science and Technology (DOST).
Results of this study put emphasis on building community resilience utilizing effective information dissemination and dynamic community-based preparedness that would lead to better disaster mitigation strategies. Communication protocols, coordination as well as control should be observed at these critical situations [52]-[53]. Similarly, it also concurs with the findings of previous studies that highlight the need to build relationships, social ties and inter-organizational coordination to sustain the strong social capital among the concerned communities with the varied organizations [24], [54], [55]. The interplay of roles of the varied organizations, including the NGOs and international volunteer organizations should be focused on implementation rather than conceptual levels [56]. Moreover, it is also best to explore the community-based adaptation measures that will have significant contribution to building more resilient communities as it is 'a community-led process, based on communities' priorities, needs, knowledge and capacities, which should empower people to plan for and cope with the impacts of climate change' and disasters like flooding [57]. Furthermore, it builds on human rights-based approaches to development that target the most vulnerable people and fully includes them in all levels of adaptation planning and implementation. In recent years, CBA has shown that it can also operate at scale but with communities remaining central to planning and action, for example through mainstreaming into government processes. Furthermore, emphasis on areas to work on should be at the forefront of discussion and decision among key players, i.e., LGU, development-oriented group, to encourage a strong community/participatory focus [54] and long-term perspective must be central to any development initiatives.

Flooding in Davao City should not only be approached within the confines of Davao City geographical boundaries. It is multi-dynamics, and cross boundary issues. In this light, it is recommended for stakeholders to harmonize efforts and initiatives and find areas to work together given their varying interests - be it political, economic and environmental. It is also best to explore the ecosystem based and communitybased adaptation measures. The latter will have significant contribution to building more resilient communities as it is 'a community-led process, based on communities' priorities, needs, knowledge and capacities, which should empower people to plan for and cope with the impacts of climate change'. Furthermore, it builds on human rights-based approaches to development that target the most vulnerable people and fully includes them in all levels of adaptation planning and implementation. In recent years, CBA has shown that it can also operate at scale but with communities remaining central to planning and action, for example through mainstreaming into government processes [57]. Good community-based adaptation (CBA) should (but does not always) have a strong consideration of ecosystems and ecosystem services. This is where the real challenge in preparing communities for climate changes adaptation. However, long term perspective must be central to any development initiatives as far planning and development interventions to mitigate if not avoid flooding in Davao City, Southern Philippines, particularly in the flood-vulnerable areas. 


\section{Towards a participatory management of flood-risk communication system for Davao City}

The findings of this research generally cover two major areas: (a) describe the existing protocols in the risk communication systems; and, (b) identify the corresponding network among the lead and implementing agencies of Davao City, Southern Philippines. These findings have implications on how to recommend an appropriate flood-risk communication and its management and envision the role of flood risk communications in developing resilience at the community levels.

Flooding has been generally accepted as the most common hazard in the world [58] and flood risks will significantly increase due to factors related to the "urbanization" of the area [18], [59], [60] as well as an effect of climate change [20], [61]. There is an increasing need among scientists, policy makers and other concerned agencies to develop and improve flood risk communication beyond the current development of hazard maps and other communication tools to relay risks about flooding [16], [18], [58], [59], [63]. However, there are certain factors that need to be considered to address the context and specific situations of the local communities [21], [64] understanding how people perceive risks on flood disasters would be useful in the designing of the most appropriate risk communication [18], [19], [64].

A critical prerequisite to effective disaster management is the minimization of related impacts through communication of risk information in a timely manner and in a format that all stakeholders can understand. Attaining this mandate can be a major challenge for disaster managers, especially in an increasingly globalized world characterized by higher levels of multi-culturalism as increasing numbers of people migrate to locations outside their culture-zones where, not only language differs, but also perceptions of and attitude towards hazard/disaster risk [65]-[69]. The challenge for disaster managers is therefore to design effective tools/strategies that not only span language differences, but also take into consideration cultural perceptions and attitudes so that the objectives of disaster risk-reduction can be achieved. Moreover, it is also best to explore the community based adaptation measures to building more resilient communities as it is 'a community-led process, based on communities' priorities, needs, knowledge and capacities, which should empower people to plan for and cope with the impacts of climate change' [49], [70] and ultimately makes community more resilient to natural disasters [40], [71]-[73] and enable them to manage and reduce the risks of these disasters [55], [62], [74]-[76].

Utilizing the results of this research - from the KII and document analysis from the concerned agencies and the communities' awareness and assessment of the communication systems and the perception, behavior and experiences of the flood-vulnerable communities and the proposed models of Simon and Alexander provided the inputs on how to design and develop a risk communication management model appropriate for the flood-vulnerable areas similar to Davao City. The following significant results have been taken into account:

1) the current communication systems implement a "topdown" approach and the feedback mechanism is weak or very limited;
2) the concerned agencies serve as the "filtering channels" needs to tailor-fit the risk messages according to the context of its target recipients;

3 ) the interoperability of the network system shows that the extent of reach does not transcend towards the household levels;

4) assessment of the risk communication system was significantly based on their familiarity of the communication tools as sources of information on flooding.

A community-based adaptation could be in the form of a participatory management model for flood-risk communication that can be integrated to address the dynamic, transactional and "localized" approach. Specifically, focusing on the following major key areas:

1) Strong community-participatory focus - encourage collective mitigation and response strategies;

2) Empower the communities to establish DRR strategies that are context-specific to their situations and experiences enhance indigenous/local DRR knowledge;

3) Provide capacity-building trainings to the community;

4) Intensify communication protocols; and,

5) Synchronization of DRR strategies from the central to local government units, involving the communities.

Fig. 7 shows the proposed participatory management model of flood risk communication (PMMFRC) highlights the different stages of the process, with the integration of the community-based inputs like the community's perception of risk, experiences on flooding, awareness of the communication systems, their attitude and assessment and their practices. Flooding as the urban crisis should be the central message of the PMMFRC, incorporating significant contribution from the flood-vulnerable communities to "contextualize" the messages that are directly related to their own situations. The amplification process should take into account the different agencies involved in the communication flow of risk communication; the information mechanisms involved followed by the selection of the appropriate communication messages that will be utilized in the communication materials for disseminated to the communities. The PMMFRC will include a portion that covers the community's inputs as to their reception of the risk messages, awareness of risk, their flooding experiences and their level of preparedness. This comes before the ripple effect is implemented. As the results of the study shows that the extent of reach as to the barangay level only covers level of officials of the barangay, it should be part of the PMMFRC that the barangay level should have its own implementing rules and regulations to account for the inclusion of the households in the barangays and that they can also be utilized as the sources of information as regards their experiences and adaptation practices on flooding incidences.

The proposed framework can be a guide to address the following concerns found to be absent in the current management of the communication system of Davao City:

1) lack of communication protocols at the barangay level;

2) insufficiency of communication approaches;

3) failure to involve all the affected residents; and,

4) lack of coordination and management on communicating flood risk messages. 


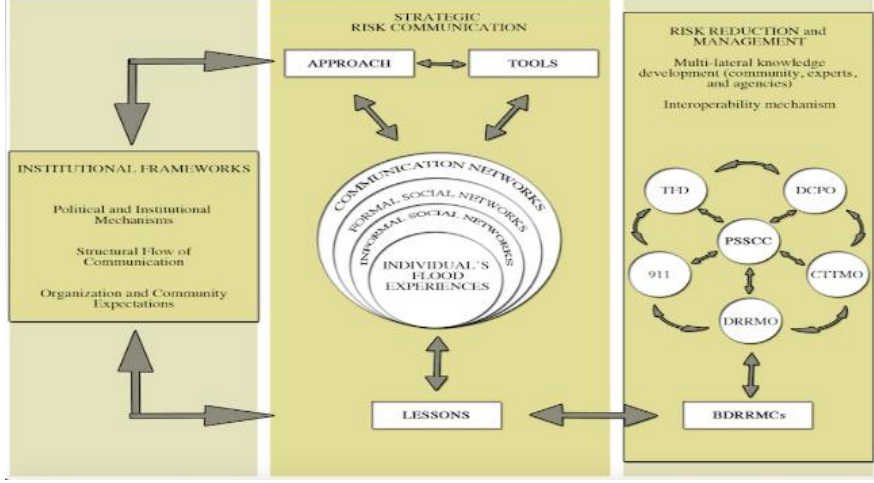

Fig. 7. A participatory management model for flood-risk communication (PMMFRC)

\section{CONCLUSION AND RECOMMENDATION}

Resilient communities are capable of bouncing back from adverse situations. They can do this by actively influencing and preparing for economic, social and environmental change. When times are bad, residents can call upon the myriad of resources that make them a healthy community. A high level of social capital means that they have access to good information and communication networks in times of difficulty.

The lack of a standardized or structured management of both risk communication and disaster response translates into poor communication interaction during and after a flooding incident happens. This is observed during the 2011 flashflood incident which resulted to 29 fatalities and destruction of properties in the Matina area. Thus, a more defined and clear flood risk communication management may help define the specific protocols that can improve the coordination and flooding responses at the community level.

A proposed participatory management model for flood risk communication (PMMFRC), therefore, may address the gaps and standardize localized approach to specific contexts of the flood vulnerable communities. It may help identify the key persons that can help plan and strategize appropriate communication messages and tools in collaboration with the residents, coordinate and manage the preparedness and response strategies to reduce risk and ensure that management, coordination and interoperability is observed at the community level.

This study would be an additional input that may become part of the development of policies as regards to empowering the communities to manage risks of flooding and develop their own risk communication systems that would be directly relevant for them. The results of this study may help develop an inclusive and sustainable approach on risk reduction management and strategies. Specifically, instead of the linear, one-way process, the framework can ensure the transactional process and a participatory communication management of the dissemination of the risk messages among the floodvulnerable communities.

\section{ACKNOWLEDGMENT}

First author conducted this study as part of her dissertation for the $\mathrm{PhD}$ Development Studies program under the supervision of Second author of the University of the Philippines, Los Banos, Laguna, Philippines. The first author gratefully acknowledges the funding granted by the $\mathrm{PhD}$
Research Scholarship from the Commission on Higher Education (CHED), South East Asia Research Center for Agriculture and Development (SEARCA) and the University of the Philippines Doctoral Studies fund.

\section{REFERENCES}

[1] P. O’Neill, Developing a Risk Communication Model to encourage community safety from natural hazards, 2014. doi.10.1.1.466.108.

[2] K. Allen, "Community-based disaster preparedness and climate adaptation: local capacity building in the Philippines". Disasters Vol. 30(1), pp. 81-101, 2006.

[3] G. Forino, J. Meding, G. Brewer and D. Niererk, "Climate Change Adaptation and Disaster Risk Reduction Integration; Strategies, Policies and Plans in three selected Australian Local Governments". International Journal of Disaster Risk Reduction. Volume 24, pp. 100108, September 2017. https://doi.org/10.1016/j.ijdrr.2017.05.021.

[4] R. Kemp, S. Parto and R. Gibson, "Governance for sustainable development: moving from theory to practice." International Journal of Sustainable Development. 8, 2005. 10.1504/IJSD.2005.007372. Accessed through https://www.researchgate.net/publication/5107694_Governance_for_ sustainable_development_moving_from_theory_to_practice.

[5] J. Koivisto and D. Nohrstedt, "A policymaking perspective on disaster risk reduction in Mozambique". Environmental Hazards Vol. 16(3), pp. 2010-2227.

2017 http://dx.doi.or/10.1080/17477891.2016.1218820.

[6] C. Kim, H. Nakanishi, D. Blackman, Ben Freyens, A. Benson, "The effect of social capital on community co-production: Towards community-oriented development disaster post disaster Recovery", Procedia Engineering, Vol 180, pp. 901-911. https://doi.org/10.1016/j.proeng.2017.04.251.

[7] S. Sammadar Yokomatsu, Muneta, Dayour, Frederick, Oteng-Ababio, Martin, Dzivenu, Togbiga, Adams, Mujeeb and Ishikawa, Hirohiko. "Evaluating Effective Public Participation in Disaster Management and Climate Change Adaptation: Insights from Northern Ghana through a User-based approach." Risks, Hazards \& Crisis in Public Policy, Vol 6(1), 2015.

[8] L.P. Dela Cruz and M.C. Pagaduan (Eds), Building Disaster-Resilient Communities: Stories and Lessons from the Philippines. Quezon City, Philippines: CSWCD-UP, 2010.

[9] R.S. Stephenson, Disasters and Development. $2^{\text {nd }}$ ed. UNDP Disaster Management Training Module, 1994.

[10] Z. A. Auzzir, R.P. Haigh and D. Amaratunga, "Public-Private Partnerships in disaster management in developing countries: a conceptual framework". Procedia Economics and Finance 18, pp. 807-814, 2014. www.sciencedirect.com.

[11] S. Carrasco, C. Chiho Oichiai and K. Okazaki, "Disaster-induced resettlement: Multi-stakeholder interactions and decision-making following tropical storm Washi in Cagayan de Oro, Philippines. Procedia - Social and Behavioral Sciences 218, pp. 35-49, 2016.

[12] L. Comfort, B. Wisner, S. Cutter, R. Pulwarty, K. Hewitt, A. OliverSmith, J. Wiener, M. Fordham, W. Peacock \& F. Krimgold, "Reframing disaster policy: the global evolution of vulnerable communities", Global Environmental Change Part B: Environmental Hazards, 1:1, pp. 39-44, 1999. DOI: 10.3763/ehaz.1999.0105.

[13] J. Mochizuki, R. Meichler, S. Hochrainer-Stigler, A. Keating, and K. Williges 'Revisiting the 'Disaster and Development' Debate Toward a Broader Understanding of Macroeconomic Risk and Resilience”. Climate Risk Management 3:39-54. Science Direct online 22 May 2014. DOI:10.1016/j.crm.2014.05.002.

[14] H. Khan, L. Vasilescu and A. Khan. "Disaster Management Cycle: A Theoretical Approach.”. 2008.

[15] D. Demeritt and S. Norbert, "Models of best practice in flood risk communication and management". Environmental Hazards 13(4), pp. 313-328, 2014.

[16] N. Leelawat, A. Suppasri, S. Kure, C.J. Yi, M.R. Mateo and F. Inamura, "Disaster warning system in the Philippines through enterprise engineering perspective: A study on the 2013 Super Typhoon Haiyan.” Journal of Disaster Research, 10(6), pp. 10411050, 2015.

[17] O. Bello, M. Khamis, C. Osorio and L.Peralta, "Mainstreaming Disaster Risk Management Strategies in development instruments: Policy briefs for selected member countries of the Caribbean Development and Cooperation Committee". 2017. https://www.cepal.org/en/publications/42175-mainstreamingdisaster-risk-management-strategies-development-instrumentspolicy. 
[18] J. De Boer, W.J. Wouter Botzen and T. Terpstra, "Improving flood risk communication by focusing on prevention-focused motivation." Risk Analysis 34(2), pp. 309-322, 2014.

[19] M.K. Lindell and R.W. Perry, "The protective action decision model: theoretical modifications and additional evidence." Risk Analysis: An International Journal 32, No. 4, pp. 616-632, 2012.

[20] T. Terpstra, M.K. Lindell and J. M. Gutteling, "Does communication (flood) risk affect (flood) risk perceptions? Results of a quasiexperimental study." Risk Analysis: An International Journal 29, No. 8, pp.1141-1155, 2009.

[21] V. Tselios and E. Tompkins, "Local government, political decentralization and resilience to natural hazard associated disasters. Environmental Hazards: Vol 16 (3), pp. 228- 2522017.

[22] L.K. Comfort, M. Dunn, D. Johnson, R.L. Skertich, "Coordination in complex systems: increasing efficiency in disaster mitigation and response". Int. J. Emergency Management Vol 2(1-2), pp. 62-80, 2004.

[23] A. Aitsi-Selmi, V. Murray, D. Heymann, B. McCloskey, E. Azhar, E. Petersen, A. ZUmla, O. Dar, "Reducing risks to health and well-being at mass gatherings: the role of the Sendai framework for disaster risk reduction". International journal of infectious diseases : IJID : official publication of the International Society for Infectious Diseases, 47, 2016, 101-104. ISSN 1201-9712 DOI https://doi.org/10.1016/j.ijid.2016.04.006.

[24] L.K. Comfort and N. Kapucu, "Inter-organizational coordination in extreme events: The World Trade Center attacks, September 11, 2001." Nat Hazards 39, pp.309-327, 2006

[25] D.M. Abramson, T. Stehling-Ariza, Y.S. Park, L. Walsh, D. Culp, "Measuring Individual disaster recovery: a sociological framework." Disaster Med Public Health Prep 4 Suppl 1:S46-54, Sep 2010. doi 10.1001/dmp.2010.14

[26] D. Alexander, "Models of Social Vulnerability to Disaster". RCCS Annual Review. Issue No. 4, 2012

[27] F. Berkes and H. Ross, "Community Resilience: Toward an Integrated Approach”. Society \& Natural Resources, 26(1), pp. 5-20, 2013.

[28] S. K. Kafle and M. Zubair, Community-based Disaster Risk Management for Local Authorities. ADPC: Bangkok, Thailand, 2006. http://www.adpc.net/v2007/Programs/CBDRM/Publications/Downlo ads/Publications/curriculum-cbdrm.pdf.

[29] S. Greiving, S.M. Fleischhauer, J. Luckenkotter, A Methodology for an integrated risk assessment of spatially relevant hazards. Journal of Environmental Planning and Management, 49:1, pp.1-19, 2006. DOI: 10.1080/09640560500372800.

[30] D. Stokols, R. Perez Lejano and J. Hipp. Enhancing the resilience of human-environment systems: a social-ecological perspective. Ecology and Society 18(1), 7. 2013. http://dx.doi.org/10.5751/ES-05301-180107.

[31] KJG Cayamanda and MA Lopez, "Community Resilience to urban flooding: A Case Study of the 2011 Flashflood in Matina, Davao City, Southern Philippines". International Proceedings of 2018 South East Asia Disaster Risk Governance Academic Seminar, 24-25 September 2018, Bangkok, Thailand.

[32] K. Sanchez and D.J. F. Sumaylo, "IEC Strategies on Risk Management and other Precautionary Practices of Residents in Barangay Matina Crossing 74-A". Proceedings of International Conference on Communication/Culture and the Sustainable Development Goals (CCSDG): Challenges for a New Generation, Chiang Mai, Thailand, 2015.

[33] R.A. M. Estacio, "A Case Study documenting the various methods used by the local barangay unit of Matina Crossing in the post-crisis phase of the Davao City flashflood". BA Thesis, College of Humanities and Social Sciences, University of the Philippines Mindanao, 2013.

[34] Davao City DRRMO Incident Report on Flashflood, 3 July 2011.

[35] M.G. Cacho, "Negotiated Space as arena of empowerment for indigenous communities in Bokod, Benguet, Philippines", PhD dissertation, UP Los Baños, 2014.

[36] R.E. Kasperson, O. Renn, P. Slovic, H.S. Brown, J. Emel, R. Goble, J. X. Kasperson, S. Ratick, "The Social Amplification Risk: A Conceptual Framework". Risk Analysis 8:2, pp.177-187, 1988. DOI: 10.1111/j.1539-6924. 1988.tb01168.x.

[37] B. Reynolds and M. Seeger, "Crisis and emergency risk communication as an integrative model". J Health Communication 10(1): pp. 43-55, Jan-Feb 2005.

[38] S. W. Littlejohn and K. Foss. Theories of Human Communication $\left(9^{\text {th }}\right.$ ed.). USA: Thomson Wadsworth, 2008.

[39] NDRRMP MANUAL 2011-2028. Accessed from http://www.ndrrmc.gov.ph/attachments/article/41/NDRRM_Plan_20 11-2028.pdf.
[40] O'Sullivan, J. J., Bradford, R. A., Bonaiuto, M., De Dominicis, S., Rotko, P., Aaltonen, J., Waylen, K., and Langan, S. J.: "Enhancing flood resilience through improved risk communications", Nat. Hazards Earth Syst. Sci., 12 (7), pp. 2271-2282, July 2012. https://doi.org/10.5194/nhess-12-2271-2012

[41] United Nations Report. unstats.un.org./unsd/mi/pdf/MDG\%20Book.pdf.

[42] M.K. Lindell and R.W. Perry, Communicating environmental risk in multiethnic communities (Vol. 7). Sage publications, 2004.

[43] DILG Region XI. 2011. Official Website of DILG Region XI Davao Region. www.region11. dilg.gov.ph

[44] RELIEFWEB. http://reliefweb.int/report/philippines/quickfacts.

[45] World Development Report 2010: An Overview. www.ReliefWeb https://www.oxfam.org/en/campaigns/5-natural-disasters-begclimate-action)

[46] R. E. Villanueva, "A Reception Analysis of the flood risk communication programs, strategies and messages of Barangay 19-B Poblacion, Davao City". BA Thesis, Department of Humanities, UP Mindanao, 2016.

[47] E. A. Saño, Advocacy and Support Work for the DRRM Law in the Philippines. In Building Disaster-Resilient Communities: Stories and Lessons from the Philippines, edited by Leonore P. Dela Cruz, Elmer M. Ferrer, and Maureen C. Pagaduan. Quezon City, Philippines: CSWCD-UP, 2010.

[48] N. Carcellar, J.C. Rayos Co \& Z.O. Hipolito, 'Addressing Disaster Risk Reduction through Community-Rooted Interventions in the Philippines: Experience of the Homeless People's Federation of the Philippines', Environment and Urbanization 23(2): pp. 365-81, 2011.

[49] A. Boquiren. August 2017. Personal Interview.

[50] N. Kalatzis, G. Routis, Y. Marinellis, M.Avgeris, J. Roussaki, S Papavassiliou, M. Anagnostou, "Semantic Interoperability for IoT Platforms in Support of Decision Making: An Experiment on Early Wildfire Detection". Sensors. 19(3). 528, 2019. DOI: $10.3390 / \mathrm{s} 19030528$.

[51] H. Kubicek, R. Cimander And H. Scholl, "Organizational Interoperability in E-Government - Lessons from 77 European GoodPractice Cases", 2011.Retrieved 02 March 2019 from https://www.researchgate.net/publication/220692861.

[52] L.K. Comfort, K. K, Ko and A. Zagorecki, "Coordination in Rapidly Evolving Disaster Response Systems". American Behavioral Scientist, Vol. 48(3): pp.295-313, 2004. DOI $10.1177 / 0002764204268987$.

[53] L.K. Comfort, 2007. "Crisis Management in Hindsight: Cognition, Communication, Coordination and Control". Public Administration Review, Special Issue, pp. 189-197, December 2007.

[54] Australian Red Cross, 2013. "Relationship matter: the application of social capital to disaster resilience". National disaster resilience roundtable report. 20 September 2012, Melbourne, Australia.

[55] N. OH, A. Okada and L.K. Comfort, "Building Collaborative Emergency Management Systems in Northeast Asia: A Comparative Analysis of the Roles of International Agencies". Journal of Comparative Policy Analysis 16(1), pp. 94-111, 2014.

[56] I. Christoplos, A. Liljelund And J. Mitchell, "Re-framing Risk: The Changing Context of Disaster Mitigation and Preparedness". Disasters 25(3), pp.185-198, 2001.

[57] H. Reid, Ecosystem- and Community-Based Adaptation: Learning from community-Based Natural Resource Management, Climate and Development, $8: 1, \quad$ pp. $\quad 4-9, \quad 2015 . \quad$ DOI 10.1080/17565529.2015.1034233.

[58] International Federation of Red Cross and Red Crescent Societies (IFRC), Philippines: Floods. Information bulletin $n^{\circ} 1$ Glide no.FL2011-000067-PHL30 Retrieved March 11, 2019 from https://reliefweb.int/sites/reliefweb.int/files/resources/Full_Report_ 1547.pdf.

[59] D. Feldman, et. al., "Communicating flood risk: Looking back and forward at traditional and social media outlets." International Journal of Disaster Risk Reduction 15, 2016, 43-51. DOI: 10.1016/j.ijdrr.2015.12.004.

[60] E. Rollason, L.J. Bracken, R.J. Hardy and A.R.G. Large, "Rethinking flood risk communication". Natural Hazards 92(3), pp. 1665-1686, March 2018.

[61] T.W. Haer, W.W. Botzen and J.C. Aerts, "The effectiveness of flood risk communication strategies and the influence of social networks insights from an agent-based model”. Environmental Science \& Policy, 60, 2016, pp.44-52, 2016

[62] E. Maidl and M. Buchecker, Raising risk preparedness by flood risk communication. Natural Hazards and Earth Systems Sciences, 15(7), pp. 1577-1595, 2015. 
[63] N. Okada and Y. Matsuda, "Risk Communication Strategy for Disaster Preparedness viewed as Multi-lateral Knowledge Development". Proceedings of IEEE International Conference on Systems, 2005, DOI:10.1109/ICSMC.2005.1571219.

[64] H. Lazrus, R.E. Morss, J.L. Demuth, J.K. Lazo and A. Bostrom, "Know what to do if you encounter a flashflood": Mental model's analysis for improving flashflood risk communication and public decision making. Risk analysis, 36(2), pp.411-427, 2016.

[65] F. L. Martin, Cultural Differences in Risk Perception: An Examination of USA and Ghanaian Perception of Risk Communication. MSc. Thesis. Virginia Polytechnic Institute and State University, 2003.

[66] W. Martin, I. Martin and B. Kent, "The role of risk perceptions in the risk mitigation process: The case of wildfire in high risk communities". Journal of Environmental Management 91(2),pp. 489498, 2009. DOI: 10.1016/j.jenvman.2009.09.007.

[67] A. Lara, X. Garcia, F. Bucci and A. Ribas, What do people think about the flood risk? An experience with the residents of Talcahuano city, Chile. Nat Hazards 85, pp.1557-1575, 2016. DOI 10.1007/s11069016-2644-y.

[68] A. Howard, et. al., "They'll tell us when to evacuate": The experiences and expectations of disaster-related communication in vulnerable groups. International Journal of Disaster Risk Reduction, 2017. http://dx.doi.org/10.1016/j.ijdrr.2007.03.002.

[69] J.B. Houston, Community resilience and communication: dynamic interconnections between and among individuals, families and organizations. Journal of Applied Communication Research. Vol 46 (1), pp.19-22, 2018.

[70] R.D. Lasco, F. B. Pulhin, P.A. Jaranilla-Sanchez, R.J. P. Delfino, R Gerpacio and K. Garcia, Mainstreaming Adaptation in Developing Countries: The Case of the Philippines. Climate and Development 1(2), pp.130-146, 2009. DOI: 10.3763/cdev.2009.0009.

[71] L.A. Mendez-Victor and C. D. Goncalves, Risks:Vulnerability, Resilience and Adaptation. Retrieved 23 Feb 2019 from http://www.iitk.ac.in/nicee/wcee/article/WCEE2012_3284.pdf.

[72] T. Mcphearson, E. Anderson, T. Elmqvist, N. Frantzeskaki "Resilience Of and Through Urban Ecosystem Services, Ecosystem Services 12, 2014, http://dx.doi.org/10.1016/j.ecoser.2014.07.012.

[73] F.H. Norris, S. P. Stevens, B. Pfefferbaum, K.F. Wyche \& R Pfefferbaum, Community Resilience as a Metaphor, Theory, Set of capacities and Strategy for Disaster Readiness. American Journal of Community Psychology, 2007. https://doi.org/10.1007/s10464-0079156-6.

[74] M.R. Magalang, Mainstreaming DRR and CCA in Mandatory Planning and Budgeting Processes of Barangays: A Case Study on Building Disaster-resilient Communities in Marinduque In Building Disaster-Resilient Communities: Stories and Lessons from the Philippines, edited by Leonore P. Dela Cruz, Elmer M. Ferrer, and Maureen C. Pagaduan. Building Disaster-Resilient Communities: Stories and Lessons from the Philippines. Quezon City, Philippines: CSWCD-UP, 2010.

[75] H. Oinas-Kukkonen, K. Lyytinen and Y. Yoo, Social Networks and Information Systems: Ongoing and Future Research Streams. J. AIS 11, 2010. DOI:10.17705/1jais.00222.

[76] C. Skinner and R. Rampersad, "A revision of communication strategies for effective disaster risk reduction: A case study of the South Durban basin, KwaZulu-Natal, South Africa", Jàmbá: Journal of Disaster Risk Studies 6(1), 2014, Art. \#132, 10 pages.

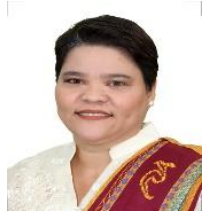

Dr. Karen Joyce G. Cayamanda is an Associate Professor in Communication from the University of the Philippines in Mindanao, with a 22 years teaching experience. Her study titled "Risk Communication Management for flood vulnerable communities of Davao City, Southern Philippines has been presented in various international conferences and have been awarded Best Paper presentation in two international conferences. She graduated $\mathrm{Ph} . \mathrm{D}$. in Development Studies from the University of the Philippines Los Banos in 2019 with a Best Dissertation award. She is a grantee of the PhD graduate studies scholarship under the Commission on Higher Education (CHED) and a PhD research scholarship recipient under the Southeast Asian Research Center for Agriculture (SEARCA) and a PhD fellow of the Doctoral Studies Program of the University of the Philippines. Her research interest is Risk Communication and Disaster Management towards strategic planning, public policy analysis and urban/rural development studies. She is a member of the Society for Research Development (SRD), Philippine Association of Media Educators (PACE), and the International Public Policy Association (IPPA).

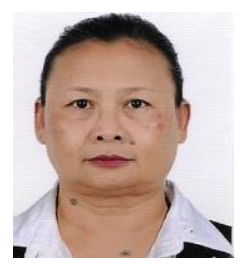

Dr. Merlyne M. Paunlagui has more than 30 years of professional experience in conducting monitoring and evaluation studies on urban poor, farmers and fisherfolks, women, children, migrant workers and families, and persons with disabilities using both qualitative and quantitative methods of research. She holds a PhD in Demography (1982) from Australian National University. She is an Associate Professor at the Institute for Governance and Rural Development and Director, Center for Strategic Planning and Policy Studies, College of Public Affairs and Development, University of the Philippines Los Baños, Philippines. 